\title{
AUTONOMOUS PLATFORMS IN THE ARCTIC OBSERVING NETWORK
}

\author{
Craig M. Lee ${ }^{(1)}$, Humfrey Melling ${ }^{(2)}$, Hajo Eicken ${ }^{(3)}$, Peter Schlosser ${ }^{(4)}$, Jean-Claude Gascard ${ }^{(5)}$, \\ Andrey Proshutinsky ${ }^{(6)}$, Eberhard Fahrbach ${ }^{(7)}$, Cecilie Mauritzen ${ }^{(8)}$, James Morison $^{(1)}$, Igor Polyakov ${ }^{(9)}$ \\ ${ }^{(1)}$ Applied Physics Laboratory, University of Washington, 1013 NE 40 ${ }^{\text {th }}$ St, Seattle, WA 98105-6698, USA \\ Email: craig@apl.washington.edu; morrison@centre.edu \\ (2) Institute of Ocean Sciences, 9860 West Saanich Road, PO Box 6000, Sidney V8L 4B2, B.C., Canada, \\ Email: mellingh@dfo-mpo.gc.ca \\ (3) Geophysical Institute, University of Alaska, 907 Yukon Dr, Fairbanks, AK 99709, USA, \\ Email: hajo.eicken@gi.alaska.edu \\ (4) Lamont Dougherty Earth Observatory, Columbia University, Palisades NY 10964-8000 USA, \\ Email: schlosser@ldeo.columbia.edu \\ (5) Université Pierre et Marie Curie, 4 place Jussieu 75005 Paris, France, Email: gascard@lodyc.jussieu.fr \\ ${ }^{(6)}$ Woods Hole Oceanographic Institution, 266 Woods Hole Road, Woods Hole, MA 02543, USA, \\ Email: aproshutinsky@whoi.edu \\ (7) Alfred-Wegener-Institut für Polar und Meeresforschung, Postfach 120161, D-27515 Bremerhaven, Germany, \\ Email: Eberhard.Fahrbach@awi.de \\ ${ }^{(8)}$ Norwegian Meteorological Institute, P.O.BOX 43, Blindern, N-0313 Oslo, Norway, Email: c.mauritzen@met.no \\ ${ }^{(9)}$ International Arctic Research Center, University of Alaska, 907 Yukon Dr, Fairbanks, AK 99709, USA, \\ Email: igor@iarc.uaf.edu
}

\begin{abstract}
Autonomous platforms (e.g. floats, ice-based observatories, (IBOs) and gliders) can contribute scalable, flexible elements to the Arctic Observing Network (AON), providing access to remote, icecovered regions and enabling persistent, sustained sampling and broad spatial coverage of the deep basins, marginal ice zone, shallow boundaries and gateways. Floats, gliders and IBOs excel at providing year-round measurements over extended (years) time periods, while their relatively modest per-platform operating costs permit deployment in quantities that are large enough to provide unprecedented spatial coverage. These platforms can be efficiently operated in large numbers and employ operating modes and logistics that can readily respond to evolving observational priorities. Autonomous instruments can be used in tandem with conventional approaches to create a sustainable AON that retains the ability to adapt to rapidly evolving environmental conditions and advances in understanding that drive shifts in observational priorities. The flexibility provided by autonomous approaches will also help the AON balance between the long-term needs of climate studies and the short-term demands of providing relevant data products to Arctic stakeholders. Recent IPY (International Polar Year) successes with autonomous technologies, such as the International Arctic Buoy Program's Pan-Arctic array, the IBO array and under-ice navigation and operation of autonomous gliders at regional scales, place the community in a position to contemplate wider adoption, though significant hurdles remain. Challenges include development of a basin-scale acoustic navigation and communications network, development of miniaturized,
\end{abstract}

energy-efficient biogeochemical sensors suitable for long-term autonomous deployment and international coordination, both for support and for broad access that spans the EEZs (Exclusive Economic Zones) of the Arctic nations. The AON should exploit autonomous technologies and foster their development for Arctic applications, with an eye toward using these systems as key building blocks for the construction of a sustainable, long-term observing system.

\section{INTRODUCTION}

Rapid Arctic environmental change, recently exemplified by the 2007 summertime sea ice minimum, presages broad shifts in global climate and exerts socioeconomic and climate impacts that extend beyond the Arctic itself. Arctic change must be monitored and understood both due to the Arctic's role in global climate and to inform efforts directed at managing and mitigating impacts. Motivated by these needs, this paper discusses the objectives and shape of an Arctic Observing Network (AON) and, specifically, the role the new generation of autonomous observing technologies might play.

Within the global climate system, the Arctic Ocean is a source of freshwater and a sink of heat for the thermohaline circulation. Surface waters carry heat to high latitude where its loss to the atmosphere drives densification and produces a return flow of water at depth. Convection thus ventilates the high-latitude outcrops of layers that plunge to much greater depth in temperate oceans, setting sub-surface density structure and sequestering carbon in the ocean's interior. In contrast, precipitation in the Arctic accumulated in river 
discharge feeds an equatorward freshwater flux near the ocean's surface. Changes in Arctic fresh-water discharge may impact the strength and character of the Atlantic Meridional Overturning Circulation (AMOC) by modulating deep-water formation in the North Atlantic, the strength of boundary currents and their delivery of fresh water to the ocean gyres.

Ocean-ice interactions play key roles. Contrasts between inflowing Pacific and Atlantic waters, riverine discharge, brine rejection from sea ice and mixing maintain a strong halocline, which insulates the ice from the warmer deeper waters. The rapid decline in summertime sea ice extent and the extreme sea ice minimum observed in 2007 illustrate both the Arctic amplification of climate variation and the various pathways via which the Arctic interacts with global climate. These connections also motivate efforts to observe, model and predict high latitude variability.

Arctic environmental change has profound societal impacts within the Arctic and at lower latitude [1 and 2]. Changing ice cover, coastal circulation and weather can alter the timing of hunts, animal abundance and access for indigenous people. Shrinking summertime sea ice opens access for resource extraction and shipping routes. Resulting population growth, vessel traffic and extraction activity brings environmental and cultural impacts. Change in the Arctic outflows can alter the characteristics of the subpolar gyre, shift fronts and permit northward advance of subtropical water. Resulting changes in North Atlantic circulation may drive ecosystem shifts with impacts on carbon fixation and fisheries.

The AON must provide both extensive sustained measurements to reveal and understand Arctic change and real-time data for environmental forecasting. Stakeholders' needs for information include documentation of natural variability and change, adaptation to change, impact assessment for industrial activity, development of ocean governance and regulation, strategic planning and tactical support for offshore development, enforcement and disaster response.

Geographic remoteness and difficult operating conditions pose challenges to broad, systematic observation. Fortunately, the AON can exploit new autonomous observing technology that has transformed ocean observing at lower latitude. Ice-based observatories (i.e. the International Arctic Buoy Program) have a long successful history. Now, extended-endurance floats, gliders, drifters and moorings offer complementary capabilities for observing and relaying data from remote regions, facilitating broad spatial coverage over decades. The new technology used in combination with conventional instruments offers varied approaches for different challenges. Ongoing efforts are yielding sensors to expand the suite of autonomously observable physical and biogeochemical properties. This is an opportune time to promote their use in the Arctic.

Autonomous platforms are powerful tools for moving the AON beyond the International Polar Year 20072008 (IPY 2007-2008), during which some important regions were poorly sampled despite support to an unprecedented observational network. Although much of the IPY array would be difficult to sustain over decades, IPY did build a backbone of observational capability and momentum that can be exploited during transition to an Arctic-wide, sustained network for environmental information.

This paper focuses on autonomous platforms in an AON. It begins with discussion of integrating the needs of climate observing and stakeholders, followed by a review of the available platforms and enabling technologies that would provide geo-location and communications. These tools are then placed in the context of an integrated observing network that exploits the complementary aspects of conventional and autonomous approaches. It concludes with a vision for a future observing network. The discussion is sensitive to non-technical issues of implementation, including balancing capability against sustainability, diplomacy and the impact of observational systems on marine life.

\section{CLIMATE AND STAKEHOLDER NEEDS - NETWORK INTEGRATION}

Few dispute the urgent need for an integrated AON. Such would deliver sustained, pan-Arctic measurements to measure change and facilitate its understanding. The ultimate outcome is capability for numerical prediction of future environmental conditions with outlook from days (tactical issues) to decades (policy implications of change).

The IPY 2007-2008 facilitated a broad suite of observations of key processes in critical regions and provided prototypes for AON components. Large programs, including the U.S. National Science Foundation's Arctic Observing Network, the European Union's Developing Arctic Modeling and Observing Capabilities (DAMOCLES), Canada's ArcticNet, C3O and CATs programs and the international Nansen Basin/Canadian Basin Observing System (NABOS/CABOS) collected ocean and ice measurements over basins, slopes, shelves, shelf/slope regions and at ocean gateways to the Arctic [3]. These initiatives will yield understanding of Arctic and global change via large-scale syntheses, such as compilation of Arctic heat and freshwater budgets. However, individual national efforts must be more closely coordinated in the future to deliver long-term observations that meet stakeholders' needs while retaining flexibility for adaptation to environmental and societal change. 
The AON must balance needs for information and products relevant to stakeholders against those relevant to change. Many stakeholders' concerns are focused on issues near inhabited regions and often require real-time data delivery. Clearly, stakeholders must be engaged in the design, implementation, operation and evolution of such observing capacity. In contrast, investigations of climate require sustained measurements at key locations throughout the Arctic without high emphasis on realtime data relay. Understanding the Arctic's interaction with global climate requires wide geographical coverage encompassing boundaries, where water-mass transformation occurs, storage basins such as the Beaufort Gyre, fronts and the gateways linking the Arctic to temperate oceans. The remoteness of some key regions from Arctic population may complicate their continued justification. On the other hand, the relevance of these observations for humans at lower latitudeagricultural planning, fisheries management-will likely engage AON stakeholders beyond the Arctic.

The AON must integrate national activities, via prioritization of sites, selection of technology and methodology, coordination of implementation and logistics and coordination of data processing, dissemination and analysis.

The long-standing International Arctic Buoy Program (IABP) is a successful integrated observing system. It employs common approaches and technologies allowing interoperability between elements that are managed by separate institutions. There is broad participation, since the objectives of diverse groups benefit from the entire system, while bearing only a share of the burden. The commonality of approach facilitates the timely, open access to data and maximizes IAPB's utility.

The SEARCH (Study of Environmental Arctic Change) Sea Ice Outlook is an example of integrated analysis. It is providing a forum for forecasts of Arctic summertime sea ice extent, synthesizing diverse approaches and analyses to promote a mechanistic understanding of Arctic ice and to improve forecast skill. The Sea Ice Outlook synthesizes the creative efforts of many teams, retaining a diversity of thought that might suffer under a centralized approach.

Significant national and international effort has been invested toward planning an integrated Arctic observing system. For example, the U.S. Polar Research Board [4] and Interagency Arctic Research Policy Committee [2] discuss potential U.S. contributions to the AON. The Arctic Ocean Science Board [5] outlines an international plan for integrated Arctic observing through the IPY 2007-2008. More recently, the Arctic Regional Ocean Observing System (Arctic ROOS) provides an example of international integration, with member institutions from nine European countries working to integrate diverse observational and modeling efforts to provide operational monitoring and forecast capability (http://www.arctic-roos.org). The International Study of Arctic Change [6] facilitates cooperative, international efforts to understand the future state of the Arctic, while the Sustained Arctic Observing Network (SAON, http://www.arcticobserving.org) seeks avenues to support and govern long-term monitoring activities.

Stakeholders need low-latency delivery of data and analyses for selected regions. Delivery should not be limited to the most technically advanced methods, since potential users may not have access to broadband communications. However, with fast Internet already in many Arctic communities, indigenous hunters are using GPS (Global Positioning System), weather data and satellite imagery in their tactical planning. The PolarView program (http://www.polarview.org) provides services in near real-time to Arctic stakeholders. It is a large program that has progressed by integrating environmental information from various agencies. The national ice services of Arctic countries are key contributors; they now provide timely data access to community-based observations at the local and regional level. (e.g. [7]). Those linked to geophysical and oceanographic data have improved delivery of useful products to Arctic communities.

Arctic change demands an AON with flexibility for adaptation to evolving environmental challenges and shifting priorities. The AON must be nimble in adopting new approaches in response to rapid change. For example, most human activity concentrates in the marginal ice zone, creating demand for real-time data return in this challenging environment. Here, variable ice cover confounds both ice-borne (e.g. aircraft operations and ice-based observatories) and bottomanchored approaches to ocean observing. The barriers to real-time data return are very high because the needed direct access to the sky is unreliable and subject to environmental damage. Shrinking summertime sea ice is expanding the extent of this difficult seasonal ice zone. On the other hand, this change offers new opportunities, such as air-deployment of instruments into open water and summertime ships' access to regions previously blocked by multi-year ice. Decreasing ice cover may also force AON to respond to increased importance of air-sea interaction, sea state, internal waves and mixing. Observing needs are also likely to change with increased understanding of the Arctic system.

\section{AON AND THE ROLE OF AUTONOMOUS PLATFORMS}

Autonomous technologies [e.g. floats, drifters, gliders, ice-based observatories (IBOs), AUVs (Autonomous Underwater Vehicles) and moorings] offer a range of flexible observing approaches for sustained, cost- 
effective operation over broad spatial and temporal domains. These platforms have transformed open-ocean observing [8], with large programs such as the global drifter array [9] and the Argo float network (e.g. [10]) providing operational data at weekly timescales with global coverage and gliders offering persistent observations in difficult environments such as western boundary currents and the subpolar seas. In ice-free oceans, autonomous platforms rely on the Global Positioning System (GPS) to provide geolocation and Iridium satellites for two-way communication. These two technologies provide the backbone for efficient low cost operation of arrays of autonomous observing assets. In the Arctic, ice makes satellite access unreliable for all platforms except IBOs, motivating efforts to establish acoustic networks, which provide long-range geolocation and two-way communication at short range. Autonomous platforms may also gain occasional surface access through leads, though not at a rate that is sufficient to geolocate their measurement streams. A series of community workshops explored platform technologies for Arctic observing, including the 2002 NSF-sponsored Instrumentation for Arctic Ocean Exploration workshop [11] and the more recent Arctic Observing Based on Ice-Tethered Platforms workshop [12 and 13], which focused on instruments suspended from drifting ice. The Acoustic Navigation and Communications for High-Latitude Ocean Research (ANCHOR) workshop [14 and 15] explored the critical enabling technologies of acoustic navigation and communications, which are needed to provide services analogous to GPS (navigation) and Iridium satellite telephone (communications) for subsea oceanographic instrumentation operating in the ice-covered Arctic. Most recently, the 2008 Arctic Observation Integration Workshops [16] included a component focused on the evolving role of autonomous platforms and the iAOOS report [17 and 18] provides an overview of ocean observing activities undertaken during the IPY 20072008.

\subsection{Status of Autonomous Technologies for Arctic Observing Following the IPY 2007-2008}

\subsubsection{Ice-Based Observatories}

Drifting sea ice provides a stable platform for deploying a wide range of autonomous instruments designed to sample the upper ocean, ice and atmosphere. These systems, collectively known as Ice-Based Observatories (IBOs), range in complexity from the relatively simple IABP buoys to multi-instrument drifting sites that might include upper-ocean sampling using profilers suspended from the ice and extensive sea ice measurements collected using the Cold Regions Research and Engineering Laboratory's (CRREL) Ice Mass Balance (IMB) Buoys. IBOs can also be exploited to provide acoustic navigation and communications links for platforms operating beneath the ice.

Deployed as an element of some IBOs, Ice-tethered Profilers (ITPs) developed at the Woods Hole Oceanographic Institution (WHOI) and Polar Ocean Profilers (POPS) developed by the Japan Agency for Marine-Earth Science and Technology (JAMSTEC) and the MetOcean company have collected high vertical resolution temperature and salinity profiles of the upper ocean. Data from ensembles of ITP and POPS instruments are being used to construct true synoptic sections across the Arctic (by, for example, analyzing all the profiles obtained on a specific day) and map spatial fields such as fresh water anomalies (Fig. 1). Another instrument contributing to the IBO concept is the Autonomous Ocean Flux Buoy (AOFB) developed by the U.S. Naval Postgraduate School. The AOFB makes high-frequency observations in the ocean surface layer just below the ice to estimate the heat, buoyancy, and momentum fluxes between the ice and ocean.

Because IBO systems rely on the presence of perennial sea ice, rapidly decreasing summertime ice extent presents significant challenges, including operations in the marginal ice zone, the prospect of periods drifting in open water and geographic access restricted by new melt and drift patterns. Existing systems are not designed to survive break-up, open water operation or freeze-up, although there is current development of new buoy hulls capable of surviving breakup and freeze-up, of general system hardening and of low-cost, airdeployable drifters designed for ice-free oceans.

\subsubsection{Floats}

Low-cost autonomous floats, adapted from instruments used in Argo, offer the ability to sample broad spatial domains over extended (years to decades) time periods. Autonomous, Argo-style floats have been deployed in the Arctic by WHOI and by the DAMOCLES partners. The WHOI Polar Profiling Float (PPF) drifts and profiles beneath the ice, but regularly attempts to locate open water by trying to surface, relying on a reinforced antenna to survive the resulting ice collisions. The float transmits data and receives a GPS fix whenever it successfully reaches the surface, drifting without geolocation for the periods between these surfacings. The DAMOCLES floats carry compact upward-looking sonars for measuring ice-draft along their drift path, and rely on acoustic contact with an array of ice-tethered platforms for geolocation and data telemetry. The PPF has seen limited Arctic deployments with some success. An array of eight (8) PPFs, along with the first DAMOCLES floats, was deployed in summer 2008.

\subsubsection{Gliders}

Long-endurance, autonomous gliders developed at the Applied Physics Laboratory, University of Washington, have seen successful operation in an ice-covered 
environment, occupying a section across the wintertime Davis Strait. Gliders profile between the surface (or iceocean interface) and $1000 \mathrm{~m}$, navigating between waypoints using GPS whenever they can access the surface, or by trilatteration on an array of long-range acoustic navigation beacons when overhead ice prevents surfacing. Arctic gliders incorporate additional autonomy for making unassisted decisions about when and where to surface, where to navigate and how to respond to unexpected situations such as hardware malfunctions or severe navigational problems. In addition to temperature, salinity and dissolved oxygen sensors, gliders can carry a variety of optical sensors for measuring fluorescence (chlorophyll and CDOM (Colored Dissolved Organic Matter)) and multiwavelength backscatter. The glider's mobility and adaptability make it an excellent choice for operations across key sections and straits, for sampling the critical ice-ocean interface and for operations within the marginal ice zone.

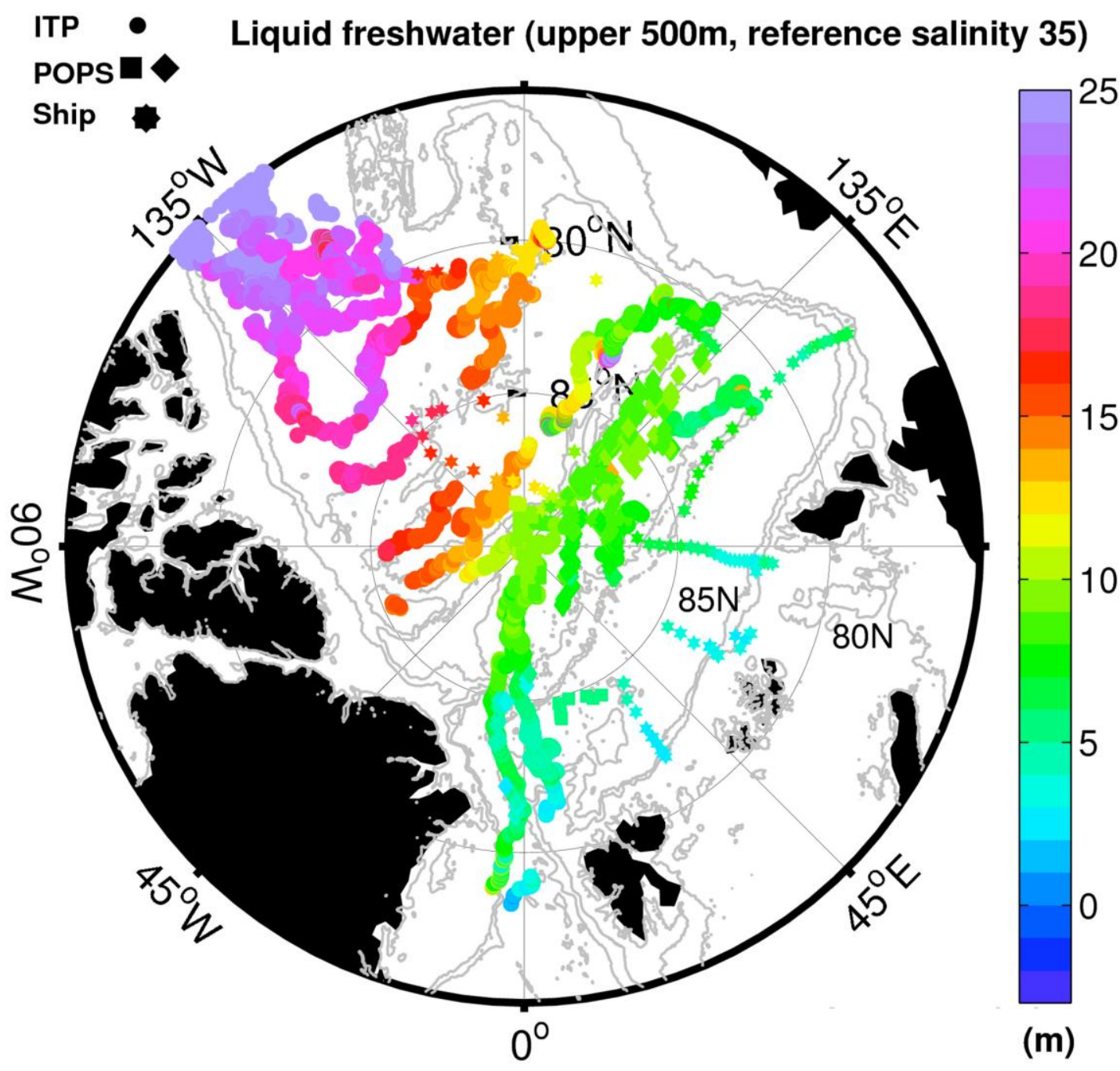

Figure 1. (from [18], figure by B. Rabe, AWI (Alfred Wegener Institute) Distribution of liquid freshwater (expressed in meters with reference salinity $\left.S_{0}=35\right)$ within the upper $500 \mathrm{~m}$, calculated from measurements collected by drifting ITPs and POPs. Data are preliminary, with some corrections still to be applied.

Seagliders have completed successful under-ice surveys across Davis Strait in December 2006 and through winter 2008/2009, with the most recent mission spanning 6 months, including 51 days and 450 miles of fully autonomous under-ice operations (Fig. 2). In addition to collecting novel, high-resolution wintertime sections and demonstrating system capability, these missions provided valuable data for refining under-ice autonomy, improving system capabilities and understanding mid-frequency $(780 \mathrm{~Hz}$, see below) sound propagation in ice-covered environments. Ongoing development work includes refinements to under ice capabilities, acoustic communications to enable data transfer, integration of new sensors and 
enhanced endurance, with the goal of achieving sufficient endurance to operate from one ice-free season

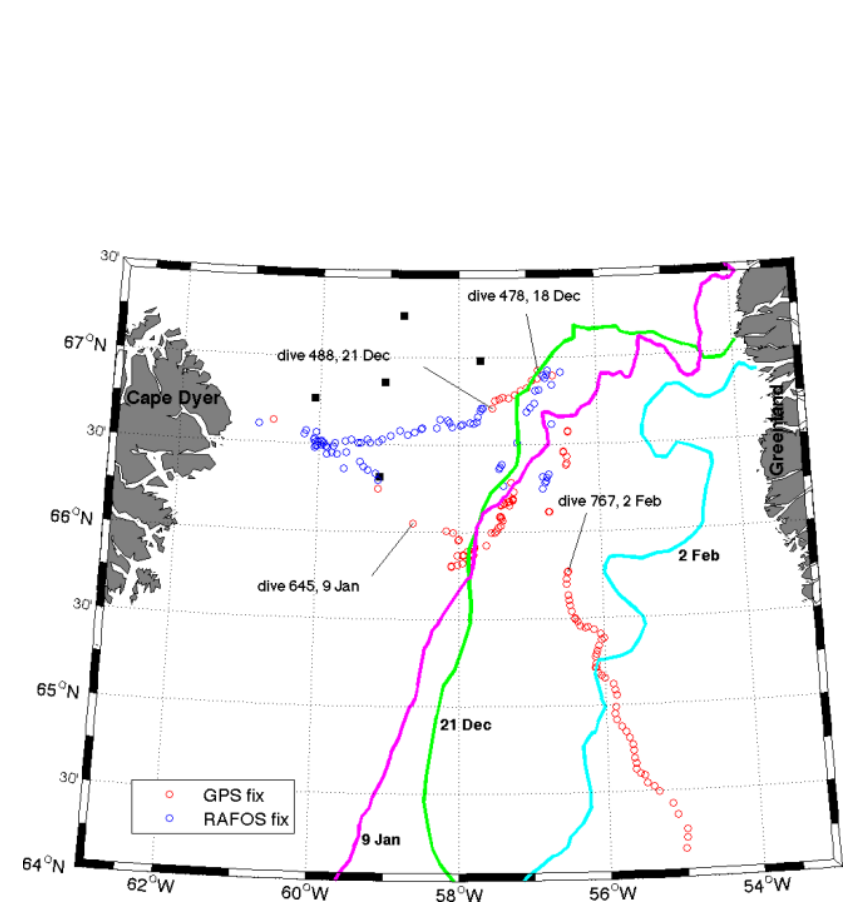

(a)

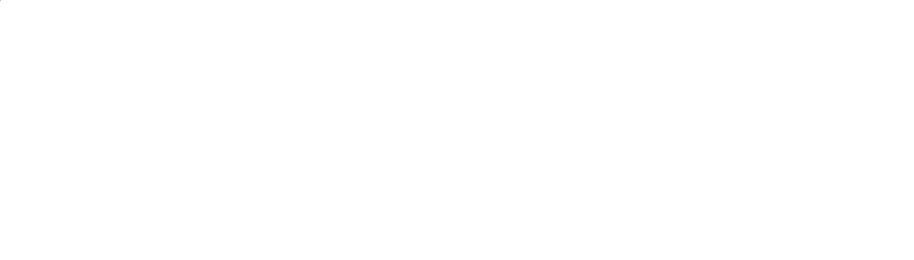

Figure 2. (a) Seaglider track for one under-ice section. Green (21 Dec), pink (9 Jan) and light blue (2 Feb) lines mark the ice edge (as defined by the Canadian Ice Service). Small circles mark glider profile positions, with red indicating GPS positions and blue indicating positions derived from real-time acoustic ranging. The glider surfaced frequently near the ice edge (likely the marginal ice zone) and found leads several times even when well inside the ice-covered region. After completing this section, the glider transited south for recovery offshore of Nuuk. (b) Temperature (color) and potential density (contours) across Davis Strait. The light grey bar across the top of the section marks ice extent, while the adjoining light blue bar indicates open water. The glider collected measurements to within a few meters of the ice-ocean interface with roughly $5 \mathrm{~km}$ horizontal resolution. (c) Salinity (color) and potential density (contours) plotted as described in (b).

\subsubsection{Moorings}

Moorings offer unprecedented temporal resolution, extensive payload capacity and the ability to make persistent measurements at a few key locations. Conventional mooring operations depend on ship support for deployment and recovery, which can restrict access to ice-covered waters. Moorings can also be deployed and recovered using aircraft support by landing on the ice directly at the desired site. Although such moorings are subject to the rather severe limitations of transportation by light aircraft, Canadian and U.S. researchers have successfully used specialized lightweight designs for waters between 30 and 4000-m depth since the 1970s. Advances in mooring hardware and instrument technologies allow three-year deployments, with periodic data upload available via acoustic modem. Ice-threatened regions such as shallow shelves and the ice-ocean interface remain problematic for moored instrumentation, though new technologies that: (1) profile only occasionally into the threatened region or (2) are inexpensive (and can thus be deployed in large numbers) and return data even if the sensing elements have been destroyed, have shown success during recent IPY deployments. Because moorings offer generous payload handling (relative to other autonomous platforms), the available sensors range 
from the relatively mundane (e.g. temperature, conductivity and water velocity) to autonomous autoanalyzers capable of collecting long nutrient concentration time series and optical instruments for classifying and counting zooplankton.

\subsubsection{Propeller-Driven Autonomous Underwater Vehicles}

Faster, propeller-driven autonomous vehicles provide useful platforms for conducting short-duration, rapidly occupied synoptic surveys and process studies. This class of AUV has been employed for tasks ranging from cable laying, to under-ice mapping, to collecting measurements of turbulence beneath the Arctic ice. The newest AUVs, such as Hydroid's REMUS (Remote Environmental Measuring UnitS), are compact and relatively easy to use, lowering the logistical barriers that have limited their application to Arctic research.

\subsubsection{Navigation and Communications}

In ice-free oceans, autonomous platforms rely on the Global Positioning System (GPS) to provide geolocation and Iridium Satellite communications for telemetering data and instructions. When ice cover denies access to the surface, these platforms must rely on acoustics for navigation and communications. Existing systems used to support float and glider operations in ice-free and ice-covered regions rely on 'mid-frequency' $(260 \mathrm{~Hz}$ or $780 \mathrm{~Hz})$ acoustics to provide navigation for domains up to several hundred kilometers across. Such a system is currently employed in the seasonally ice-covered Davis Strait, and is planned for deployment in Fram Strait [19]. Tests have also been conducted using mid-frequency navigation sources suspended from a small array of drifting IBOs. However, signal loss from reflections off the ice limits ranges to $\mathrm{O}(100 \mathrm{~km})$, making larger domains impractical. Previous Arctic acoustic propagation experiments conducted at $\mathrm{O}(10 \mathrm{~Hz})$ demonstrate that these low-frequency signals remain coherent through surface reflections over basin-scale ranges, thus offering a technology for supporting basin-wide navigation from a modest number of acoustic sources. Possible impacts on marine mammals warrant careful consideration although the appreciable operating depth and short duty cycle of these sources should ease concerns. Commercial products provide short-range $\mathrm{O}(1 \mathrm{~km})$, high-rate acoustic communications, but acoustic communication over longer ranges, especially in the presence of overhead ice, would be restricted to relatively slow data rates and is the subject of ongoing development efforts.

\subsubsection{Sensors}

Autonomous platforms currently have access to a growing suite of compact, low-power sensors for physical and biogeochemical variables. In addition to standard temperature, conductivity and water velocity measurements, sensors now include various optical measurements that can be interpreted as proxies for key components of the oceanic carbon balance, chlorophyll and CDOM fluorometers, dissolved oxygen, nitrate concentration and turbulence. Significant investments in biological and chemical sensor development should yield additional sensors, hopefully including $\mathrm{pH}$ and additional nutrients, within a timeframe relevant to AON.

\subsubsection{How Autonomous Observing Addresses AON Priorities}

To be sustainable, AON must be relevant and cost effective in meeting intertwined science and stakeholder needs. Both factors strongly influence what is observed, where observations are made and how quickly they are relayed to users. It is neither appropriate nor practical to specify these needs here. The following discussion provides a conceptual framework for the challenging pragmatic decisions of the future and a broad outline for how this framework might shape the use of autonomous observing.

Users' needs for environmental data fall into three overlapping domains: policy, strategy and tactics. That of policy is closely tied to governance and, by the nature of the questions, science. Data in this domain are used for understanding environmental change, long-term planning, disaster reduction, regulation and environmental protection. The geographic scope of policy applications is large-national or Arctic-wide in the AON context; its outlook is long term, from decade to century; its need for current data is not pressing; since policy cannot constantly react to new information, an update every 1-5 years is sufficient. Among the three domains, policy places the highest value on long observational records. Good policy decisions require the scientific understanding of Arctic change and its impacts, which will be built from this data.

The domain of strategy belongs equally to government, science, industry and communities. Environmental data in this domain are used for the medium-term planning (seasons to years to decades) of expensive or hazardous activities. Examples include the feasibility of shipping across the Arctic Ocean and the design of structures for producing Arctic offshore oil. The geographic scope for individual strategic applications is more focused than for policy, but areas of interest can be well visited or remote; its outlook is medium term, from season to decade; its need for current data is quite demanding updates at intervals from days to a year are typical. Because strategic decisions are frequently made on statistical grounds (recurrence intervals, risk-benefit considerations), this domain also requires long observational records. 
The domain of tactics spans all levels of society - Is there risk in travelling to the floe edge? What is the best route for a barge through ice to Camden Bay? The geographic scope for a tactical application is generally very focused, but such applications may be widely dispersed; tactical applications are generally in frequented areas-shipping routes, hunting areas, communities; their outlook is short, from hours to weeks; their need for current data is demandingupdates at hourly intervals may not suffice. In contrast to requirements for policy and strategy, long records have little value; the shelf life of recent data may be very short.

This conceptual framework built around broad categories of application provides general guidance for AON design and the application of autonomous approaches. The needs of policy and science dictate a pan-Arctic array that quantifies a small number of fundamental variables (e.g. ice cover and drift, sea level, ocean current, temperature and salinity, weather, basic meteorological and biological variables) at a cost that allows continued funding across several decades of operation, analogous to the challenges faced by Argo. Autonomous floats, gliders, IBOs and moorings can make significant contributions to such an array, providing broad spatial coverage, efficient access to remote sites, persistence and, by dint of scalability and (for some platforms) low cost, built-in redundancy. Such a system must be prepared to trade off more comprehensive measurement suites in favor of sustained and broadly distributed monitoring of key variables. All key components of the Arctic system should be monitored-sources (e.g. polynyas) and sinks, storage reservoirs, boundary currents, inflow and outflow pathways, etc. The marine Arctic in this context extends far beyond the 4 major basins; it also encompasses 8 shallow shelf seas, 3 deeper shelf seas (Barents, Canadian polar shelf, Baffin Bay) and 2 ice domains (annual, perennial). The SEARCH Implementation Plan [20] and the IPY observational network provide a convenient view of measurements and sites deemed critical (Fig. 3).

The AON for strategic use must address specific applications and anticipate those of the future within a footprint that allows long-term funding. Present interests, including coastal communities, shipping corridors, resource extraction and national security, define a wide ribbon around the perimeter of the Arctic Ocean that largely coincides with the horseshoe of seasonal ice running from western Russia to eastern Canada. Applications are likely to be near areas of human habitation and the list of relevant variables expands to include storm waves, surge, state of the coastal ocean, ice-drift and flow trajectories, fast ice, break-up/freeze-up dates, snow cover on ice, wildlife migration corridors, colonies, benthic and pelagic communities, human impacts (e.g. vessel noise, icebreaking, marine disposal), etc. Here, autonomous floats, gliders, low-cost moorings and 'amphibious' IBOs offer access to the challenging marginal ice zone and shallow shelves. Moreover, proximity to habitation might make routine surveys conducted by fast, heavily instrumented, propeller-driven AUVs a cost-effective approach.

The AON for tactical use has the shortest attention span, making it the easiest to define once needs are known. AON elements for tactical observations can be created and wound down as needs evolve, with less regard to past commitments, future concerns and long-term funding. On the other hand, much more capable infrastructure is needed for the timely relay, processing and dissemination of data, likely including operational capacity for real-time data assimilation and for shortterm coupled atmosphere, ocean and ice forecasts. Here, the flexibility and real-time reporting offered by autonomous approaches would allow rapid implementation of new observing elements with relatively simple re-tasking as needs evolve. Selected autonomous components of larger 'policy' and 'strategic' networks could also be reprogrammed midmission to respond to rapidly evolving needs.

\subsection{Autonomous Platforms in the Arctic Observing Network}

Autonomous floats, gliders, IBOs, AUVs and moorings provide highly scalable, flexible, cost-effective observing technologies for AON. Floats, gliders and IBOs excel at providing year-round measurements over extended (years) time periods, while their relatively modest per-platform operating costs permit deployment in quantities that are large enough to provide unprecedented spatial coverage. Most importantly, these platforms can be efficiently operated in large numbers and employ operating modes and logistics that can readily respond to evolving observational priorities. These autonomous technologies enhance AON's flexibility to meet the broad needs discussed above within a cost structure allowing prolonged (decades) observation, while interoperating with a broader range of AON approaches not discussed in this paper.

AON can usefully exploit the complementary capabilities of the various autonomous platforms (Fig. 4) to meet observing needs across a broad range of scales and operating environments. Low-cost profiling floats could characterize large-scale circulation, watermass evolution and changes in storage within the basins. Drifting IBOs could provide upper ocean profiles along with detailed sea ice and atmospheric boundary layer measurements. IBOs could also relay data collected by platforms operating beneath the ice, interrogating these instruments via acoustic modem and uploading data via satellite. However, the nature of 
Lagrangian drifts can result in a concentration of platforms in convergence zones and limits their utility for resolving structure across boundary currents and frontal zones. Gliders possess the ability to navigate between waypoints, and can thus repeatedly occupy critical sections across boundary currents, fronts and basins. Gliders might also serve as 'mail carriers', collecting data from platforms operating beneath the ice and relaying information either directly (when they access open water) or through IBO gateways. Instruments on moorings can provide detailed time series of ice and ocean variables at critical sites such as polynyas, ice massifs, gateways, continental shelves, slopes and ridges. The suite of in situ measurements would be analyzed alongside data acquired through satellite remote sensing. Though not discussed in this paper, Kwok et al. [21] provide an excellent example that illustrates the power of such a combined analysis.

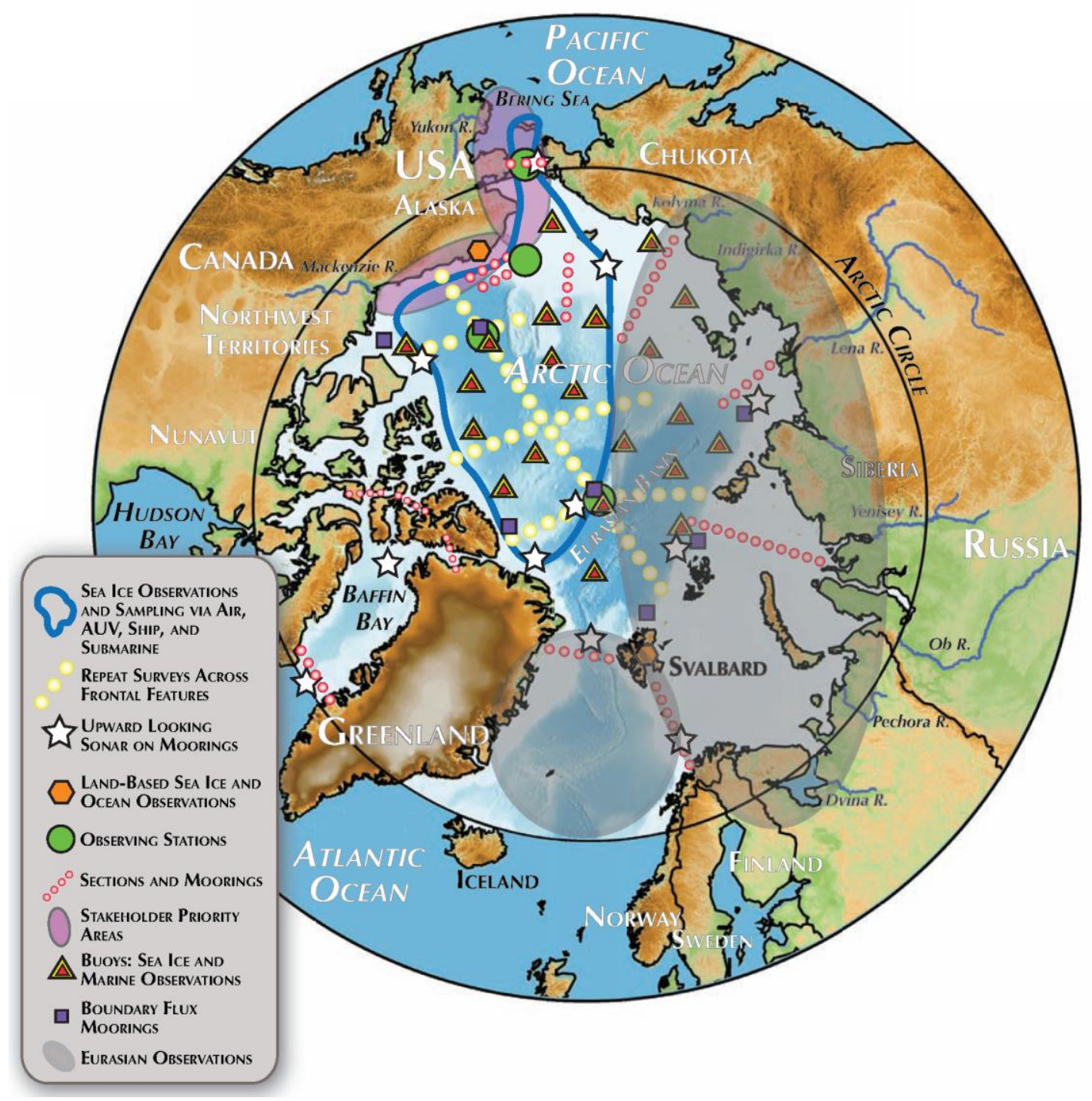

Figure 3. (From [20]) Priority areas for ocean and sea ice measurements. High priority areas include gateways for exchange between Arctic and Subarctic basins, major storage basins, the broad shelf-slope systems and sections across critical frontal regions. Many sites target long timescale change and sit far from centers of human activity, while others (pink shading) might deliver more targeted tactical information to stakeholders. Drifting autonomous assets (e.g. IBOs)

would be distributed through the deep basis as depicted by the red triangles. Moorings and gliders monitor the gateways and shelf-slope regions (red circles and grey squares) while gliders conduct repeat occupations of crossbasin sections that span key frontal features (yellow circles). 


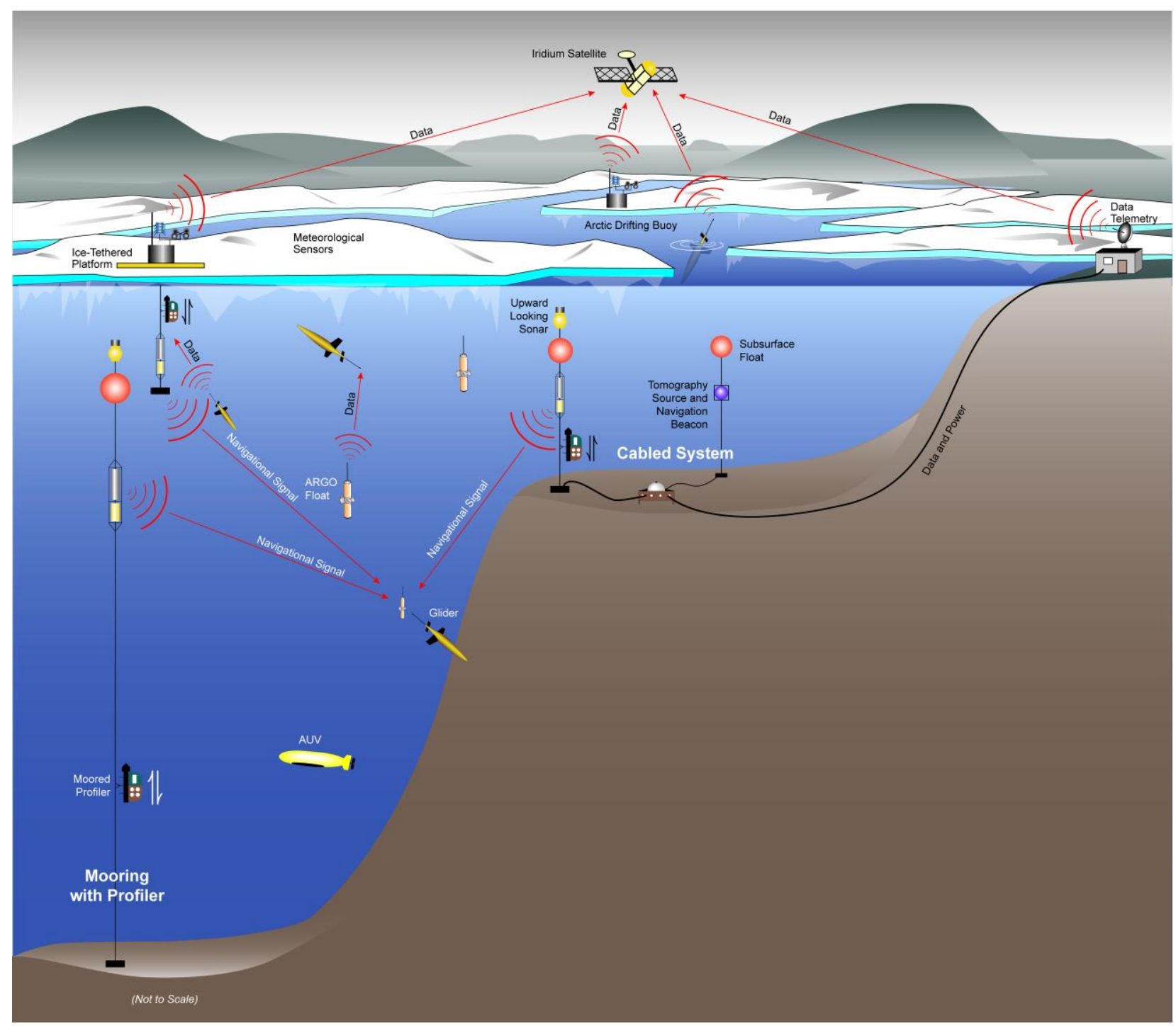

Figure 4. Autonomous platforms and their interactions in the Arctic Observing Network. Gliders, floats, IBOs and moorings sample the deep basins, slope regions and gateways while moored technologies collect measurements over the shelves. IBOs, and glider and floats (when they find open water) communicate via satellite. When ice blocks surface access, gliders, floats, moored data depots and IBOs form a somewhat diffuse store-and-forward network, passing data between themselves and eventually back to the laboratory by forwarding through and IBO or through an vehicle that has found a lead. Faster, more capable propeller-driven AUVs conduct routine sections in regions where logistics allow, supporting a broad suite of sensors and acting as a truck to interrogate instruments isolated beneath the ice and carry their data back to shore. Autonomous platforms navigate using low-frequency acoustic signals broadcast by moored sound sources and, perhaps, by some sources operating from a shore-side cable. Low frequency sources might also be used for acoustic thermometry.

Ship and aircraft-based hydrography would continue to provide important measurements, such as biogeochemical variables, tracers and ecosystem data that cannot be collected by the limited sensor suite available to autonomous platforms. These data are needed for both calibration and to inform interpretation. Where logistically practical, larger, propeller-driven AUVs capable of supporting more extensive sensor payloads than smaller mobile platforms, might supplement or replace ship- or aircraft-based surveys.
Ship and aircraft support will also be needed to service autonomous platforms and their supporting navigation and communications infrastructure. The high cost and finite capacity of logistics to maintain AON will be a continuing reality, despite the huge savings that accrue from reliance on autonomous installations. Logistical costs and challenges will continue to exert a very strong incentive for engineering durability and longevity into the platforms for AON and for building redundancy into 
the arrays as insurance against untimely loss or failure of observing elements.

Autonomous platforms operating within AON will rely on the acoustic navigation and communications. Although existing systems have successfully employed mid-frequency navigation systems and exploited occasional open-water access to utilize Iridium satellite communications, efficient, scalable autonomous operations in AON will require a more comprehensive, Arctic-wide system. A recent community workshop outlined a three-tier system to provide basin-, regionaland local-scale navigation, low-bandwidth one-way (source-to-platform) basin- and regional-scale communication and high-bandwidth, short-range twoway telemetry. Low-frequency $(10-100 \mathrm{~Hz})$ sources would provide acoustic navigation signals capable of retaining coherence at trans-Arctic ranges, allowing a small $(<10)$ number of carefully chosen sites to provide a GPS-like (though likely less accurate) navigation system for platforms operating anywhere in the Arctic basin (Fig. 5). Basin-scale sources might also provide tomographic signals for Arctic Ocean thermometry, monitoring integrated heat content at weekly to decadal timescales. Nested within this, a mid-frequency $(\sim 1$ $\mathrm{kHz}$ ) system would provide $\mathrm{O}(1 \mathrm{~m})$ accuracy, regionalscale (hundreds of kilometers) navigation and lowbandwidth, one-way source-to-platform communication. Tasked to support process studies and mapping efforts, these sources would be relatively inexpensive and sized small enough to facilitate a wide range of deployment options (e.g. moorings, ice-tethered platforms, transport aboard small, ice-capable aircraft). Lastly, existing acoustic modem technologies would provide high-data rate, two-way communications.

The design and operation of acoustic infrastructure must integrate efforts to understand and mitigate the impacts of sound on marine mammals. Several whale (bowhead, beluga and narwhal) and seal (ringed, bearded, harp, hooded, ribbon and spotted) species as well as walrus and polar bears are of great importance to human communities culturally and as a food source. Given that Arctic environmental change already threatens both marine mammal and human populations, any acoustic infrastructure must be designed to minimize the introduction of additional stress. AON investigators will thus need to work directly with Arctic residents and marine mammal specialists to develop mitigation strategies. These might include choosing frequencies, amplitudes, source depths and locations to minimize impact, limiting source duty cycles and temporary deactivation of selected system elements in response to the presence of transient animals. AON elements are already carrying hydrophones to track and count marine mammals, providing data to assess and improve mitigation strategies and to assist with studies of the animals themselves.

\section{SUMMARY}

Autonomous platforms can contribute scalable, costeffective, flexible elements to the Arctic Observing Network, enabling persistent, sustained sampling and broad spatial coverage of the deep basins, shallow boundaries and gateways. These technologies have seen extensive use in lower-latitude environments, where they have dramatically altered the community's approach to ocean observing, as well as a variety of early successes in the Arctic itself. Recent IPY successes with autonomous technologies place the community on the threshold, ready to contemplate wider adoption. Broad, easy access to satellite-based geolocation (GPS) and communications (Iridium) allowed autonomous approaches to scale efficiently in the ice-free oceans. Within the Arctic, ice often blocks access to the sea surface, forcing autonomous operations within AON to rely on acoustic navigation and communications. Regional scale solutions (hundreds of kilometers) have been successfully implemented, but a basin-scale system is needed for AON to fully exploit the capabilities of floats, gliders and AUVs. Although preliminary studies have outlined this system's shape, significant effort must be directed at defining scope and cost of this potentially critical AON component.

Beyond the significant challenges posed by technology development and logistics, international collaboration will be required to overcome issues of sustainability and pan-Arctic access. The network's operations and maintenance costs will likely be borne by a consortium of the nations bordering the Arctic. At the national level, agencies responsible for basic research and operational observing must team to develop models for supporting long-term, integrated measurement efforts capable of spanning the immediate, tactical needs of Arctic stakeholders while also producing the broadly distributed, long time series needed to investigate climate change and its impacts. Moreover, AON operates in a rapidly changing environment and must thus retain sufficient flexibility to adapt to new constraints and shifting observational priorities. A marriage of the basic research community's responsive, curiosity-driven approach with the operational community's long-term commitment and focus the delivery of useful information may help AON span its broad objectives. AON will require access that spans the EEZs of the Arctic nations. Mobile and drifting platforms may pass though multiple EEZs through their useful lifetimes, while there are high-priority sites for moored assets and acoustic navigation and communication beacons within the EEZs of nearly all the Arctic countries. Investigations into many of the important questions of circulation, watermass modification and sea ice evolution demand measurements that span national boundaries. Sensitivities surrounding exploration of newly 
accessible regions, territorial disputes and issues surrounding data access complicate AON operations across multiple EEZs. International collaboration and coordination will play a critical role in identifying sustainable funding models and securing pan-Arctic access for AON. Calder et al. [3] address these issues in detail.

Moving beyond the IPY 2007-2008, AON should exploit autonomous technologies to enhance the spatial and temporal coverage of the existing network, with an eye toward establishing a sustainable, long-term observing system. Beyond the examples shown in this paper, autonomous approaches could address challenging AON priorities that include measurements in marginal ice zones, the atmospheric boundary layer, distributed ice thickness measurements and surveys across important frontal zones. The establishment of long-range acoustic navigation and communications should be given high priority, as this infrastructure is needed to achieve the scalability that has radically altered lower-latitude observing.

\section{ACKNOWLEDGMENTS}

The authors gratefully acknowledge support from our sponsors during the preparation of this paper. The U.S. National Science Foundation supported Lee (ARC0632231 and ARC0633885), Eicken (OPP0632398), Schlosser, Proshuntinsky (ARC0856531, ARC0806306, ARC08049010 and ARC0856479), Morison (OPP352754 and OPP0634226) and Polyakov (ARC0327664). The U.S. National Oceanic and Atmospheric Administration (2000175) and National Aeronautics and Space Administration (NNH07ZDA001N-CRYO) supported Polyakov. Melling was supported by the Canada Program for IPY 2006-SR1-CC-135 and Canada PERD (Programme for Educational Research and Development): Northern Regulatory Research 12225. The Norwegian Research Council supported Mauritzen through the IPY program project 176096/S30. Gascard and Fahrbach were supported by the European Union in the 6th Framework Programme for Research and Development, contracts 018509 and 03711.

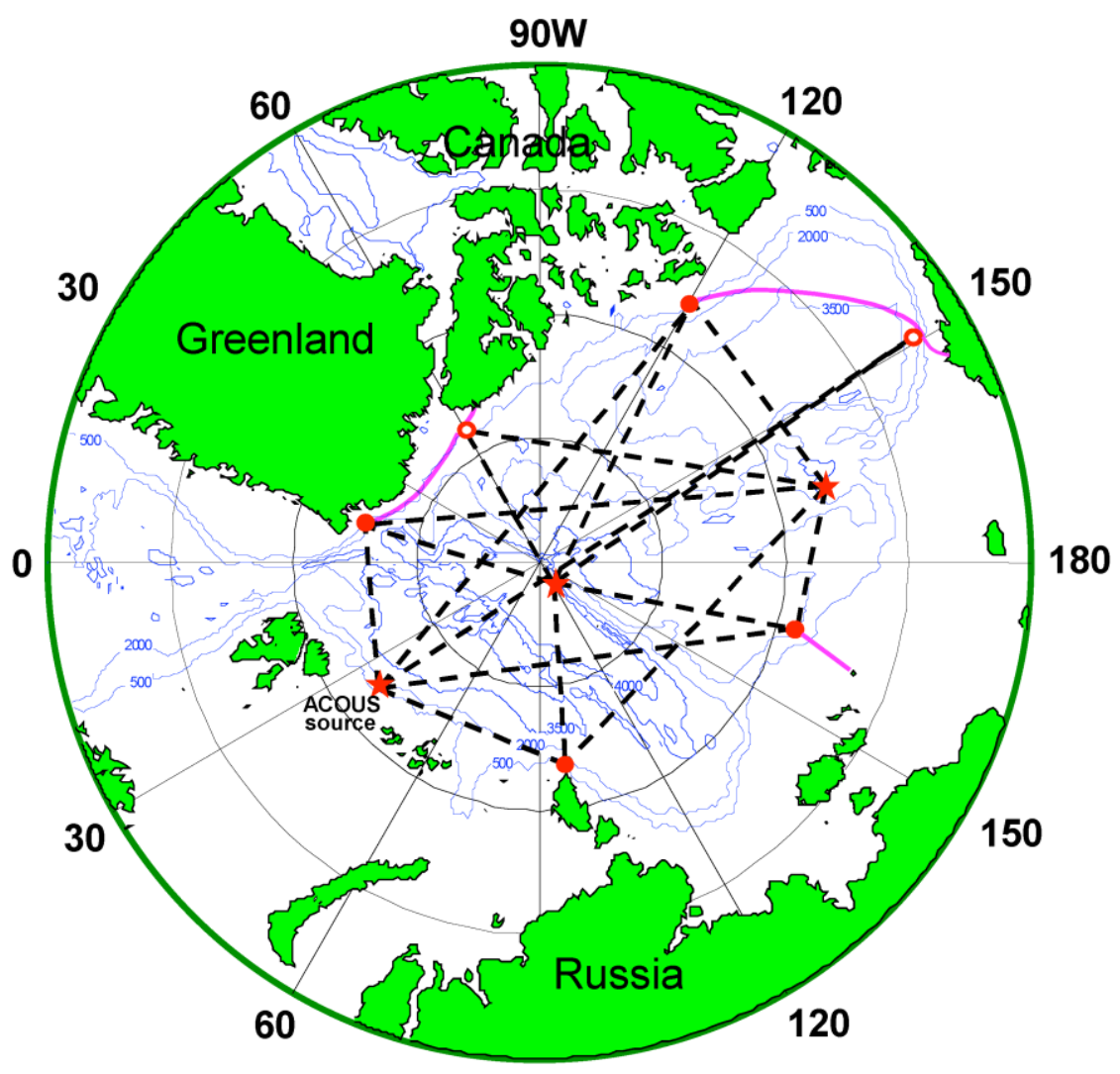

Figure 5. (Provided by P. Mikhalevsky, SAIC (Science Applications International Corporation)) Notional low-frequency $(10-100 \mathrm{~Hz})$ acoustic navigation and thermometry array. Black dashed lines indicate paths for acoustic thermometry while pink lines mark possible cables for supporting selected moorings. Array geometry and assumed transmission ranges were informed by low-frequency results stemming from the ACOUS (Arctic Climate Observations using Underwater Sound) program. A network such as this could supply acoustic navigation for the entire Arctic basin. 


\section{REFERENCES}

1. SEARCH SSC (2001). SEARCH: Study of Environmental Arctic Change, Science Plan, 2001. Polar Science Center, Applied Physics Laboratory, University of Washington, Seattle, $91 \mathrm{pp}$

2. IARPC (2007). Arctic Observing Network: Toward a U.S. Contribution to Pan-Arctic Observing, Arctic Research of the United States Volume 21, Edited by M. Jeffries, F. Korsmo, J. Calder and K. Crane, National Science Foundation, Arlington, VA, 94 pp.

3. Calder, J. \& Co-Authors (2010). "An Integrated International Approach to Arctic Ocean Observations for Society (A Legacy of the International Polar Year)" in these proceedings (Vol. 2), doi:10.5270/OceanObs09.cwp.14.

4. Polar Research Board (2006). Toward an Integrated Arctic Observing Network, The National Academies Press, Washington D.C., 116 pp.

5. AOSB (2005). The Integrated Arctic Ocean Observing System (iAOOS): An AOSB-CliC Observing Plan for the International Polar Year, Arctic Ocean Science Board, Vienna, VA, 16 pp.

6. ISAC (2009). The International Study of Arctic Change, Science Plan and Implementation, Strategy, Edited by M.S. Murray. International Study of Arctic Change Program Office, Stockholm, Sweden, 58 pp.

7. Mahoney, A., and S. Gearheard (2008). Handbook for Community-based Sea Ice Monitoring. National Snow and Ice Data Center Special Report, 14, Boulder, CO, 34 pp.

8. Rudnick, D.L. and M.J. Perry (Editors) (2003). ALPS: Autonomous and Lagrangian Platforms and Sensors, Workshop Report, 64 pp.

9. Niiler, P. (2001). The world ocean surface circulation, Ocean Circulation and Climate-Observing and Modeling the Global Ocean, Edited by J. Church, G. Siedler, and J. Gould. Academic Press, San Diego, 193204.

10. Roemmich, D., G. C. Johnson, S. Riser, R. Davis, J. Gilson, W. B. Owens, S. L. Garzoli, C. Schmid, and M. Ignaszewski (2009). The Argo Program: Observing the global oceans with profiling floats. Oceanography, 22(2), 24-33.

11. Arctic Instrumentation Working Group (2002). Instrumentation for Arctic Ocean Exploration, Monterey Bay Aquarium Research Institute, 45 pp.

12. Proshutinsky, A., A. Plueddemann, J. Toole and R. Krishfield (Editors) (2004). Ice-Based Observatories: A Strategy for Improved Understanding of the Arctic Atmosphere-Ice-Ocean Environment Within the Context of an Integrated Arctic Observing System, Woods Hole Oceanographic Institution, Woods Hole, MA, 65 pp.

13. Proshutinsky et al. (2004). An array of ice-based observatories for Arctic studies, EOS, Transactions, $A G U, 85(46), 484$.
14. Lee, C. M. and J. I. Gobat (2006). Acoustic Navigation and Communication for High-Latitude Ocean Research Workshop, EOS, Transactions, AGU, 87(27), 268.

15. ANCHOR Working Group (2008). Acoustic Navigation and Communication for High-Latitude Ocean Research, Applied Physics Laboratory, University of Washington, Seattle, WA, 54 pp.

16. SEARCH (2008). Arctic Observation Integration Workshops Report, SEARCH Project Office, Arctic Research Consortium of the United States (ARCUS), Fairbanks, Alaska, 63 pp.

17. Dickson, R. R. and iAOOS PIs (2008). The Integrated Arctic Ocean Observing System (iAOOS) in 2007. Arctic Ocean Sciences Board, Vienna, VA, 82 pp.

18. Dickson, R. R. and iAOOS PIs (2009). The Integrated Arctic Ocean Observing System (iAOOS) in 2008. Arctic Ocean Sciences Board, Vienna, VA, 82 pp.

19. Worcester, P. \& Co-Authors (2010). "Acoustic technologies for observing the interior of the Arctic Ocean" in these proceedings (Annex), doi:10.5270/OceanObs09.

20. SEARCH (2005). Study of Environmental Arctic Change: Plans for Implementation During the International Polar Year and Beyond, Arctic Research Consortium of the United States (ARCUS), Fairbanks, Alaska, 104 pp.

21. Kwok, R. \& Co-Authors (2010). "Combining Satellite Altimetry, Time-Variable Gravity, and Bottom Pressure Observations to Understand the Arctic Ocean: A Transformative Opportunity" in these proceedings (Vol. 2), doi:10.5270/OceanObs09.cwp.50. 